\title{
Terres de Sienne. Problèmes de représentation de la nature et du paysage dans la peinture siennoise (1270-1480)
}

Thèse de doctorat de l'Université de Bourgogne, sous la direction de Daniel Russo, décembre 2003

\section{Anne-Laure Imbert}

\section{(2) OpenEdition}

\section{Journals}

Édition électronique

URL : https://journals.openedition.org/cem/991

DOI : 10.4000/cem.991

ISSN : 1954-3093

Éditeur

Centre d'études médiévales Saint-Germain d'Auxerre

Édition imprimée

Date de publication : 15 août 2004

ISSN : 1623-5770

\section{Référence électronique}

Anne-Laure Imbert, «Terres de Sienne. Problèmes de représentation de la nature et du paysage dans la peinture siennoise (1270-1480) », Bulletin du centre d'études médiévales d'Auxerre | BUCEMA [En ligne], 8 | 2004, mis en ligne le 14 février 2007, consulté le 22 septembre 2022. URL : http:// journals.openedition.org/cem/991; DOI : https://doi.org/10.4000/cem.991

Ce document a été généré automatiquement le 22 septembre 2022.

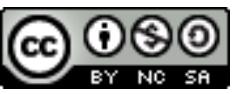

Creative Commons - Attribution - Pas d'Utilisation Commerciale - Partage dans les Mêmes Conditions 4.0 International - CC BY-NC-SA 4.0

https://creativecommons.org/licenses/by-nc-sa/4.0/ 


\section{Terres de Sienne. Problèmes de représentation de la nature et $\mathrm{du}$ paysage dans la peinture siennoise (1270-1480)}

Thèse de doctorat de l'Université de Bourgogne, sous la direction de Daniel Russo, décembre 2003

Anne-Laure Imbert

1 Lorsque l'on regarde le panorama du Bon Gouvernement d'Ambrogio Lorenzetti, au Palais Public de Sienne, on se trouve confronté à un monde tout entier, qui est à la fois une morphologie naturelle, un réseau de relations économiques et politiques, un idéal collectif, en somme un rêve, que l'allégorie contrôle, mais qui tient en lui toute la vérité concrète d'un pays. C'est l'alchimie qui opère une telle transfiguration du sol, en faisant $\mathrm{du}$ pays un paysage, que nous avons voulu éclairer dans cette étude. Comment se construit à travers toute l'histoire stylistique de la peinture médiévale à Sienne, un système langagier assez complexe pour dire de mieux en mieux le contado. Comment, loin de constituer un unicum, la fresque lorenzettienne s'insère dans une longue conquête historique, engagée dès le moment où l'on fait le bilan de l'héritage byzantin, mais encore poursuivie dans le champ rétréci de la culture du second Trecento, et portée à sa pleine maturation dans l'expérience multiple du Quattrocento, au point que l'expression de la nature pourrait constituer le noyau même de la spécificité siennoise, là où l'école se forme comme telle, où elle s'affirme encore face à la tradition constructive et narrative de Florence. La construction du paysage comme champ d'affirmation d'un style historique siennois dans le domaine propre de l'art n'oblitère pas du reste sa nature sociale : nous comprenons précisément la peinture comme le lieu où s'élabore la conscience collective du paysage selon des enjeux économiques (la conquête et l'organisation des sols), politiques (la Commune engendre une représentation du territoire), religieux (le paysage, milieu créé, s'offre encore comme champ de construction symbolique du discours), et littéraires (la peinture utilise les formes et les 
topiques rendues manifestes par la convention poétique et rhétorique). C'est dans le croisement de ces diverses attentes, de ces divers regards sur la terre et le monde siennois que se diversifient et se confortent les formules d'où peut surgir, finalement, la trame d'un authentique discours paysager. Il convient dès lors de réviser un discours trop fréquent dans les histoires générales du paysage, qui fait au mieux du Bon Gouvernement une parenthèse éblouie, dans un Moyen Âge incapable de dire encore, ou mieux, l'espace, la nature. En revenant aux définitions génériques, mais surtout philosophiques du paysage, nous entendons affirmer ici la pleine validité esthétique de l'expérience siennoise, et sa fonction sans doute fondamentale dans l'aventure européenne du paysagisme.

INDEX

Mots-clés : peinture siennoise 